\title{
Nucleic acid sequence-based amplification (NASBA) for the identification of mycobacteria
}

\author{
Gabrielle M. E. van der Vliet, ${ }^{1 *}$ Rianne A. F. Schukkink, ${ }^{2}$ Bob van Gemen, ${ }^{2}$ \\ Peter SChePERs ${ }^{1}$ and PAul R. KLATSER ${ }^{1}$ \\ ${ }^{1}$ Royal Tropical Institute, N.H. Swellengrebel Laboratory of Tropical Hygiene, Meibergdreef 39, \\ 1105 AZ Amsterdam, The Netherlands \\ ${ }^{2}$ Organon Teknika, Boseind 15, 5281 RM Boxtel, The Netherlands
}

(Received 31 March 1993; revised 4 June; accepted 25 June 1993)

\begin{abstract}
Nucleic acid sequence-based amplification (NASBA), an isothermal amplification technique for nucleic acids (NA), was investigated for the species-specific identification of mycobacteria. A set of primers was selected from a highly conserved region of the 16S rRNA sequence of mycobacteria sandwiching a variable sequence to perform amplification of mycobacterial RNA. Species-specific probes for the $M$. tuberculosis complex, M. aviumparatuberculosis, $M$. intracellulare and $M$. leprae were hybridized in-solution with the amplified nucleic acids of 10 pathogenic mycobacteria and 11 closely related bacteria, as well as with human-derived NA in an enzyme-linked gel assay (ELGA). Each probe was shown to hybridize specifically to the amplified single-stranded RNA of the corresponding species. Thirty-two clinical isolates of $M$. tuberculosis strains from different parts of the world were correctly identified by NASBA using the $M$. tuberculosis-complex-specific probe. In combination with the ELGA, NASBA could identify mycobacteria rapidly, i.e. in less than $6 \mathrm{~h}$. The relative simplicity and rapidity of this technique makes it an attractive tool for species-specific identification of mycobacteria.
\end{abstract}

\section{Introduction}

The members of the genus Mycobacterium include some important human pathogens, such as Mycobacterium tuberculosis and $M$. leprae. Infection with mycobacteria can be detected by conventional acid-fast staining of clinical specimens, providing the number of bacteria present in the sample is more than $10^{4} \mathrm{ml}^{-1}$ (Bates, 1979). However, identification of the species is required for clinical and epidemiological purposes.

Identification of mycobacteria can be based on phenotypic properties, such as biochemical characteristics or antigenic composition, or on genetic properties, as expressed in characteristic nucleotide sequences in the genome. Phenotypic determination is still routinely the most common strategy, but is time-consuming and laborious. Genotypic identification is a more rapid and reliable approach for identification of mycobacteria (Gonzalez \& Hanna, 1987). The necessity of prior culture

*Author for correspondence. Tel. 20 5665441; fax 206971841.

Abbreviations: NA, nucleic acid(s); NASBA, nucleic acid sequencebased amplification; ELGA, enzyme-linked gel assay. may be circumvented through the use of nucleic acid amplification techniques, which allow rapid and sensitive detection of species-specific nucleotide sequences (Meier et al., 1993).

16S rRNA is an appealing target for the purpose of genotypic characterization for two reasons (Woese, 1987). First, the 16S rRNA contains sequence information allowing identification of mycobacteria at the species level (Böddinghaus et al., 1990a, b; Rogall et al., $1990 a, b$; Stahl \& Urbance, 1990; Teske et al., 1991). Secondly, an advantage is the high copy number of rRNA in each cell, which makes rRNA easier to detect than targets that occur in a low number of copies. Amplification of a genus-specific stretch of the 16S rRNA with the polymerase chain reaction (PCR), followed by sequence analysis of the PCR product (Rogall et al., 1990b) or hybridization with speciesspecific probes (Böddinghaus et al., 1990b) has been successfully applied for identification of mycobacteria. A drawback of this method is the need for sophisticated equipment, such as a thermocycler (Stoker, 1990; Telenti et al., 1993).

An alternative approach is the nucleic acid sequencebased amplification (NASBA) technique (Compton, 
1991) to selectively amplify mycobacterial 16S rRNA. Isothermal nucleic acid amplification of RNA in NASBA is achieved through the concerted action of AMV reverse transcriptase (RT), T7 RNA polymerase and RNAase $H$. The reaction starts with a non-cyclic phase, in which a downstream primer containing a tail-sequence of the T7-promotor sequence, anneals to the single-stranded target sequence. Through the action of AMV-RT, cDNA is formed. The RNAase $\mathrm{H}$ hydrolyses the RNA from the RNA-DNA hybrid, which results in a single strand of DNA to which the upstream primer can anneal. The AMV-RT synthesizes, through its DNA polymerase activity, a second DNA strand producing a doublestranded DNA intermediate with a transcriptionally active promotor sequence. The T7 RNA polymerase generates from this intermediate single-stranded RNA copies (100-1000), which serve as a template in the nowcyclic phase of NASBA. Apart from the fact that NASBA can amplify nucleic acids a billionfold within 1.5 to $2 \mathrm{~h}$, it has the advantage over other amplification techniques in that it is a continuous, isothermal process, without the need for specialized equipment. The entire procedure, from amplification to identification, can be performed within a day. NASBA has already been successfully applied to the detection of RNA viruses (Kievits et al., 1991). We have investigated NASBA followed by 'in-solution' hybridization in an enzymelinked gel assay (ELGA) to detect the amplified singlestranded RNA products with non-radioactive mycobacterial species-specific probes. We focused on $M$. tuberculosis, $M$. avium and $M$. leprae, important pathogens in immunocompetent patients and, in the case of the first two species, also in immunocompromised patients.

\section{Methods}

Bacterial strains. Table 1 shows the bacterial strains that were used in this study. The cultivable mycobacteria were grown on LöwensteinJensen slants for 2-3 weeks. $M$. leprae was isolated from spleen tissue of an experimentally infected armadillo (Dasypus novemcinctus Linn.) as recommended by the World Health Organization (1980). Other bacteria which might be found in human samples or which are closely related to mycobacteria (see Table 1), were used for controls (courtesy of Dr R. J. van Ketel, Department of Medical Microbiology, Academic Medical Centre, Amsterdam, The Netherlands). For Actinomyces israelii lyophilized bacteria were used.

$M$. tuberculosis strains isolated from patients from Tanzania $(n=16)$, Thailand $(n=8)$ and The Netherlands $(n=8)$ were grown on Löwenstein-Jensen slants. All these strains were identified by conventional microbiological identification methods and characterized as $M$. tuberculosis. They were included in the study to explore the use of NASBA on clinical isolates from distinct geographical origins.

Nucleic acid $(N A)$ isolation. All bacteria were harvested from a solid medium, except $M$. smegmatis, which was grown in Sauton medium. A suspension of the bacteria was made in $1 \mathrm{ml}$ of phosphate-buffered saline (PBS) containing 0.1\% (w/v) Tween 80 (Sambrook et al., 1989). The mycobacteria were centrifuged for $5 \mathrm{~s}$ at $13000 \mathrm{~g}$ in an Eppendorf centrifuge to remove large clumps.
All organisms were adjusted to a turbidity equivalent of a no. 4 $\mathrm{McF}$ arland barium sulphate nephelometer standard as described earlier by Verstijnen et al. (1991) and subsequently ten times diluted. A $50 \mu 1$ vol. of the diluted samples contained approximately $10^{5}$ viable mycobacteria as determined by counting the number of colony-forming units. A $50 \mu \mathrm{l}$ vol. of the diluted samples was used for lysis and NA isolation according to 'protocol $\mathrm{Y} / \mathrm{SC}$ ' described by Boom et al. (1990). In brief, the bacteria were added to a guanidinium thiocyanate (GuSCN) lysis solution (5.25 M-GuSCN, $50 \mathrm{~mm}-\mathrm{Tris} / \mathrm{HCl}, \mathrm{pH} \mathrm{6.4}$, $20 \mathrm{~mm}$-EDTA, $1.3 \%$, w/v, Triton X-100) and rapid lysis was facilitated by two cycles of heat/cold shocks: heating for $5 \mathrm{~min}$ at $100^{\circ} \mathrm{C}$ in boiling water and snap-freezing for $5 \mathrm{~min}$ at $-170^{\circ} \mathrm{C}$ in liquid nitrogen. Activated silica [50 $\mu \mathrm{l}$ silica (Sigma); $1 \mathrm{~g} \mathrm{ml}^{-1}$ suspension in $0.1 \mathrm{M}-\mathrm{HCl}$ ] was added to bind the released NA. The NA-silica complex was washed twice with GuSCN washing solution (5.25 M-GuSCN; $50 \mathrm{~mm}$-Tris/ $\mathrm{HCl}, \mathrm{pH} 6.4$ ), twice with $70 \%$ (v/v) ethanol and once with acetone. After drying the silica at $56^{\circ} \mathrm{C}$, the NA were eluted from the silica with $50 \mu \mathrm{R}$ RAase-free $\mathrm{H}_{2} \mathrm{O}$ and stored at $-20^{\circ} \mathrm{C}$.

Human NA were isolated in a similar fashion (kindly provided by $\mathrm{Dr}$ H. Smits, Department of Virology, Academic Medical Hospital, Amsterdam, The Netherlands). A $2 \mu \mathrm{l}$ vol. containing $270 \mathrm{ng}$ NA was tested. This amount corresponds to approximately $4 \times 10^{5}$ diploid human cells.

Total RNA isolation. The procedure for total RNA isolation was adapted from Chirgwin et al. (1979). M. tuberculosis was harvested and resuspended in $2.5 \mathrm{ml}$ of GTC (4 M-GuSCN, $25 \mathrm{~mm}$-sodium citrate, pH $7 \cdot 0,0 \cdot 5 \%$ Sarkosyl, $0 \cdot 1 \mathrm{M}-\beta$-mercaptoethanol). Lysis of the mycobacteria was facilitated by two series of alternating heat/cold shocks (see above). The GTC suspension was loaded onto a cushion of $1.5 \mathrm{ml}$ $5.7 \mathrm{M}-\mathrm{CsCl}$ in a polyallomer centrifuge tube. The tube was filled up with GTC (final volume about $6 \mathrm{ml}$ ), and centrifuged in a swing-out rotor at $150000 \mathrm{~g}$ for $15-18 \mathrm{~h}$ at $25^{\circ} \mathrm{C}$. The supernatant was removed leaving a

Table 1. Bacterial species and strains

\begin{tabular}{clll}
\hline \hline No. & \multicolumn{1}{c}{ Strain/source } & \multicolumn{1}{c}{ Species } & Origin* \\
\hline 1 & 5544 & Mycobacterium africanum & RIVM \\
2 & 3875 (serovar 2) & $\begin{array}{l}\text { Mycobacterium avium } \\
\text { Mycobacterium bovis }\end{array}$ & RIVM \\
4 & 8316 & RIVM \\
4 & - & Mycobacterium bovis BCG & SSI \\
5 & IWGMT3 (serovar 4) & Mycobacterium intracellulare & RIVM \\
6 & 1012 & Mycobacterium kansasii & RIVM \\
7 & Armadillo isolate & Mycobacterium leprae & KIT \\
8 & $138601-24$ & Mycobacterium paratuberculosis & CDI \\
9 & 3442 & Mycobacterium scrofulaceum & RIVM \\
10 & 4514 & Mycobacterium tuberculosis & RIVM \\
11 & 103.62 & Actinomyces israelii & CBS \\
12 & Clinical isolate & Corynebacterium belfanti & AMC \\
13 & Clinical isolate & Corynebacterium J.K. & AMC \\
14 & Clinical isolate & Escherichia coli & AMC \\
15 & Clinical isolate & Haemophilus influenzae & AMC \\
16 & Clinical isolate & Klebsiella pneumoniae & AMC \\
17 & Clinical isolate & Legionella pneumophila & AMC \\
18 & Clinical isolate & Nocardia asteroïdes & AMC \\
19 & Clinical isolate & Pseudomonas aeruginosa & AMC \\
20 & Clinical isolate & Staphylococcus aureus & AMC \\
21 & Clinical isolate & Streptococcus pneumoniae & AMC \\
& &
\end{tabular}

* RIVM, National Institute of Public Health and Environmental Protection, Bilthoven, The Netherlands; SSI, Statens Serum Institut, Copenhagen, Denmark; KIT, Royal Tropical Institute, Amsterdam, The Netherlands; CDI, Central Veterinary Institute, Lelystad, The Netherlands; CBS, Centraalbureau voor Schimmelcultures, Baarn, The Netherlands; AMC, Academic Medical Centre, Department of Medical Microbiology, Amsterdam, The Netherlands. 
layer of $1-1.5 \mathrm{ml} \mathrm{CsCl}$ and the walls of the tube were rinsed with GTC, keeping the RNA pellet covered with a $\mathrm{CsCl}$ layer. After decanting the remaining $\mathrm{CsCl}$, the bottom of the tube containing the RNA pellet was cut off. The pellet was rinsed twice for 3 min with $100 \mu l$ of ice-cold $70 \%$ ethanol. The RNA was resuspended in $450 \mu$ of RNAase-free $\mathrm{H}_{2} \mathrm{O}$. This $450 \mu \mathrm{l}$ vol. of RNA suspension was transferred to a new tube

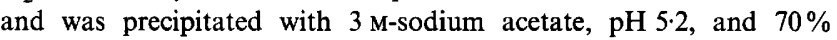
ethanol. After washing the RNA pellet with $70 \%$ ethanol, it was dried and resuspended in $100 \mu$ l of RNAase-free $\mathrm{H}_{2} \mathrm{O}$. The concentration of RNA was determined spectrophotometrically.

Selection of primers and probes. The primers and probes used in this study are listed in Table 2. Primers OT 727 and OT 737 were chosen from a highly conserved region of the nucleotide sequence of the mycobacterial 16S rRNA genes (Rogall et al., 1990a; Liesack et al., 1990). These primers facilitate the amplification of 16S rRNA when there is sufficient homology between the primers and target. From the published sequence data these primers were calculated to be approximately 200 nucleotides apart depending on the species of mycobacteria (Rogall et al., 1990a). This primer set sandwiches a variable sequence in mycobacteria; stretches of sequence that occur in this region are specific for certain species. On the basis of these characteristic sequences probes were constructed for identification (Böddinghaus et al., 1990a; Stahl \& Urbance, 1990; Teske et al., 1991). Previously described species-specific probes for the detection of NA derived from $M$. tuberculosis (OT 999), M. avium-paratuberculosis (OT 998), M. intracellulare (OT 997) and $M$. leprae (OT 852) were used in this study (Böddinghaus et al., 1990 $a$; Teske et al., 1991). A species-specific probe for $M$. smegmatis (OT 851) was chosen by us from the same variable region.

$N A S B A$. The NASBA reactions were performed as described by Kievits et al. (1991) with some modifications. The final volume of the reaction mixture was $25 \mu \mathrm{l}$. First, a $21 \mu \mathrm{l}$ vol. prereaction mixture was assembled so that the final concentration for $25 \mu \mathrm{l}$ would be: $40 \mathrm{~mm}-$ Tris/HCl, pH 8.5, $12 \mathrm{~mm}-\mathrm{MgCl}_{2}, 42 \mathrm{~mm}-\mathrm{KCl}, 5 \mathrm{~mm}-\mathrm{DTT}, 1 \mathrm{~mm}$ of each dNTP, 2 mM of each NTP, $15 \%$ (v/v) DMSO, 12 U RNA guard

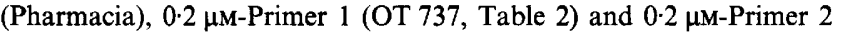
(OT 727, Table 2). After addition of $2 \mu 1$ of target RNA the tubes were incubated for $4 \mathrm{~min}$ at $65^{\circ} \mathrm{C}$ in order to uncoil the tertiary and secondary structures of the $16 \mathrm{~S}$ rRNA. The reaction mixtures were then directly transferred to $41^{\circ} \mathrm{C}$. After $2 \mathrm{~min}, 2 \mu \mathrm{l}$ of an enzyme mix was added to the tubes, resulting in a final volume of $25 \mu$, containing $0.1 \mu \mathrm{g} \mathrm{BSA} \mu \mathrm{l}^{-1}, 38 \mathrm{U}$ T7 RNA polymerase (Pharmacia), $8 \mathrm{U}$ AMVRT (Seikagaku), 0 1 U RNAase H (Pharmacia). Isothermal amplification of the RNA target was performed by incubation of these samples at $41{ }^{\circ} \mathrm{C}$ for $2 \mathrm{~h}$. Reaction mixtures containing no target NA served as negative controls. The amplification products were either directly processed for detection analysis by Southern blotting or ELGA (see below) or stored for $2-4$ weeks at $-20^{\circ} \mathrm{C}$.

Blotting procedure. For detection of the amplification products, $7 \mu \mathrm{l}$ of each reaction mixture was loaded onto a $2 \%$ agarose (Pronarose, SpheroQ, The Netherlands) gel containing ethidium bromide (Sambrook et al., 1989). The separated products were blotted onto ZetaProbe (Bio-Rad) membrane using a vacuum blot apparatus (Pharmacia) and hybridized with a ${ }^{32} \mathrm{P}$-labelled oligonucleotide (OT 999 and OT 851, Table 2) (Sambrook et al., 1989). The membranes were exposed to X-ray film (Kodak) for $4 \mathrm{~h}$.

$E L G A$. A rapid non-radioactive 'in-solution' hybridization assay (ELGA) was developed to identify the NASBA products with speciesspecific horseradish peroxidase (HRP) 5'-labelled oligonucleotide probes (ELGA probes). Hybridization was performed without the need for prior denaturation of the NASBA products, since the product of NASBA is mainly single-stranded RNA. Stringent hybridization conditions are compulsory to distinguish the mismatches in a target by the ELGA probe. After hybridization, excess non-hybridized ELGA probes were separated from the homologous hybridized product by gel electrophoresis. The free ELGA probes and the hydrized products could be directly visualized in the acrylamide gel by incubating the gel directly in substrate solution for HRP. Due to its lower mobility the homologous hybridized product migrates in the gel above the free ELGA probe.

Table 2 shows the species-specific synthetic oligonucleotides that were labelled on the $5^{\prime}$ end with HRP and used as probes in the ELGA. An ELGA hybridization was performed by mixing $1 \mu l$ of the NASBA reaction product with $4 \mu$ l hybridization solution [final concentration of this reaction mix was $1 \times \operatorname{SSC}(0.15 \mathrm{M}-\mathrm{NaCl} ; 0.015 \mathrm{M}$-sodium citrate), $5 \%$, v/v, glycerol, $2 \mathrm{~mm}$-sodium phosphate buffer, $\mathrm{pH} 7.0,0.01 \%$ bromophenol blue, $0.01 \%$ xylene cyanol and $10^{10}$ molecules of HRPlabelled probe]. The hybridization reaction mixtures were incubated for $15 \mathrm{~min}$ at $45^{\circ} \mathrm{C}$. These stringency conditions, which were sufficient to distinguish at least two mismatches with the oligonucleotide, were used for all ELGA probes tested. Hybridization reaction mixtures $(2.5 \mu \mathrm{l})$ were then directly applied onto a $7 \%$ acrylamide gel, containing $0.04 \%$ $(w / v)$ dextran sulphate. After electrophoresis, the hybridized amplification products and the ELGA probes in the gel were visualized by staining with $80 \mathrm{ml}$ substrate solution (125 $\mu \mathrm{g} \quad 3,3^{\prime}, 5,5^{\prime}-$ tetramethylbenzidine $\mathrm{ml}^{-1}$ and $0.003 \% \mathrm{H}_{2} \mathrm{O}_{2}$ in $0.1 \mathrm{M}$-sodium citrate buffer, $\mathrm{pH} 5 \cdot 2$ ). The gel was incubated in the substrate solution for approximately $10 \mathrm{~min}$ at room temperature before blue-stained bands appeared. The gel was fixated by incubation in $50 \%(\mathrm{v} / \mathrm{v})$ methanol overnight at room temperature.

\section{Results and Discussion}

\section{Specificity of NASBA}

The NASBA primers (OT 727 and OT 737; Table 2) directed the amplification of an approximately $200 \mathrm{nt}$ sequence of the 16S rRNA containing a region which is variable in mycobacteria. Previously described speciesspecific probes (Table 2) were used for identification of the NASBA products derived from ten different mycobacteria and eleven other relevant bacteria. Identification of the NASBA products was performed using the ELGA technique, an 'in-solution' hybridization assay. Electrophoresis of the hybridization reaction mixtures is necessary to discriminate between free ELGA probe (fast mobility) and ELGA probe that has specifically hybridized to the NASBA product (slow mobility). Both products could be visualized directly in an acrylamide gel (Fig. 1).

The specificity of the NASBA in combination with ELGA is shown in Fig. 1. Probe OT 999 hybridized with amplified RNA from $M$. africanum, $M$. bovis, $M$. bovis BCG and $M$.tuberculosis (Fig. $1 a$, lanes 1, 3, 4 and 10, respectively). Probe OT 999 was shown previously to be specific for M. tuberculosis (Böddinghaus et al., 1990a). As expected, hybridization occurred between amplification products derived from other members of the $M$. tuberculosis complex due to their identical 16S rRNA sequences (Rogall et al., 1990 b).

Probe OT 998 hybridized with amplified RNA from $M$. avium (Fig. 1b, lane 2) and $M$. paratuberculosis 
Table 2. Sequences of primers and probes used in amplification of $16 S \mathrm{r} R \mathrm{RA}$

\begin{tabular}{|c|c|c|c|}
\hline Oligo & Sequence & Positions* & Function \\
\hline OT 727 & $\begin{array}{l}5^{\prime} \text { AAC ACG TGG GTG- } \\
\text { ATC TGC CCT GCA } 3^{\prime}\end{array}$ & $77-100$ & $\begin{array}{l}\text { Upstream primer, } \\
\text { highly conserved } \\
\text { region of myco- } \\
\text { bacterial } 16 \mathrm{~S} \text { rRNA† }\end{array}$ \\
\hline OT 737 & $\begin{array}{l}5^{\prime} \text { AAT TCT AAT ACG- } \\
\text { ACT CAC TAT AGG- } \\
\text { GAG TGT GGC CGG- } \\
\text { TCA CCC TCT CA } 3^{\prime}\end{array}$ & $262-284$ & $\begin{array}{l}\text { Downstream primer, } \\
\text { highly conserved } \\
\text { region of myco- } \\
\text { bacterial } 16 \mathrm{~S} \text { rRNA } \dagger\end{array}$ \\
\hline OT 851 & $\begin{array}{l}5^{\prime} \text { CTG GTC GCA TGG- } \\
\text { CCT GGT AG } 3^{\prime}\end{array}$ & $148-168$ & $M$. smegmatis probe $\uparrow$ \\
\hline OT 852 & $\begin{array}{l}5^{\prime} \text { AAG CTT TTT GCG- } \\
\text { GTG CAG GAT G 3' }\end{array}$ & $172-196$ & M. leprae probe $\ddagger$ \\
\hline OT 997 & $\begin{array}{l}5^{\prime} \text { TTA GGC GCA TGT- } \\
\text { CTT TAG GT } 3^{\prime}\end{array}$ & $148-168$ & $M$. intracellulare probe $\$$ \\
\hline OT 998 & $\begin{array}{l}5^{\prime} \text { CAA GAC GCA TGT- } \\
\text { CTT CTG GT 3' }\end{array}$ & $148-168$ & $\begin{array}{l}\text { M. avium paratuberculosis } \\
\text { probe§ }\end{array}$ \\
\hline OT 999 & $\begin{array}{l}5^{\prime} \text { CGG GAT GCA TGT- } \\
\text { CTT GTG GT } 3^{\prime}\end{array}$ & $148-168$ & $\begin{array}{l}M . \text { tuberculosis complex } \\
\text { probe§ }\end{array}$ \\
\hline
\end{tabular}

* Rogall et al. $(1990 a)$.

$\dagger$ This study.

$\ddagger$ Teske et al. (1991).

$\S$ Böddinghaus et al. (1990a).

(a)

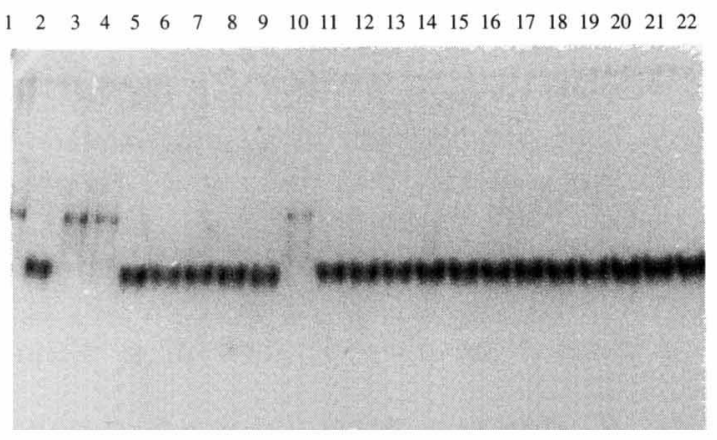

(c)

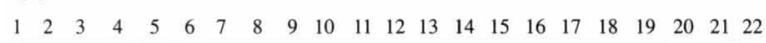

$\begin{array}{lllllllllllllllllllll}2 & 3 & 4 & 5 & 6 & 7 & 8 & 9 & 10 & 11 & 12 & 13 & 14 & 15 & 16 & 17 & 18 & 19 & 20 & 21 & 22\end{array}$

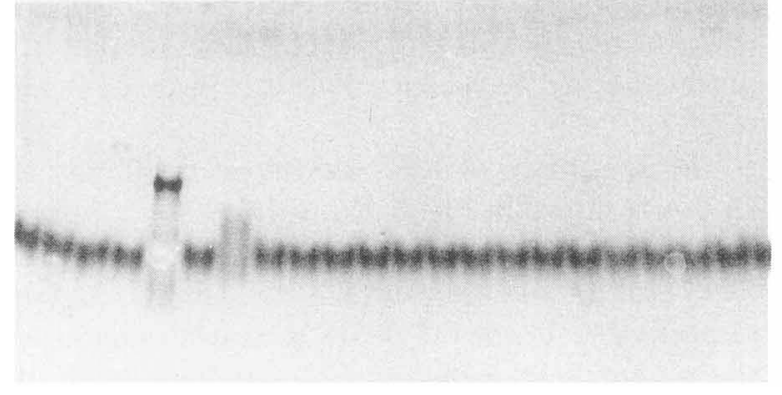

(b)

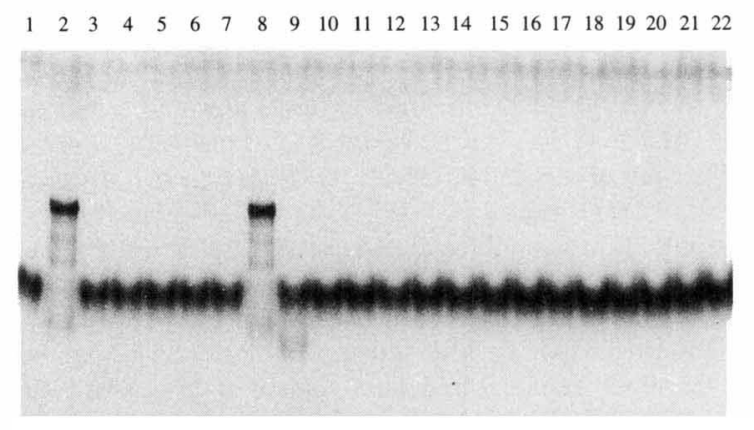

(d)

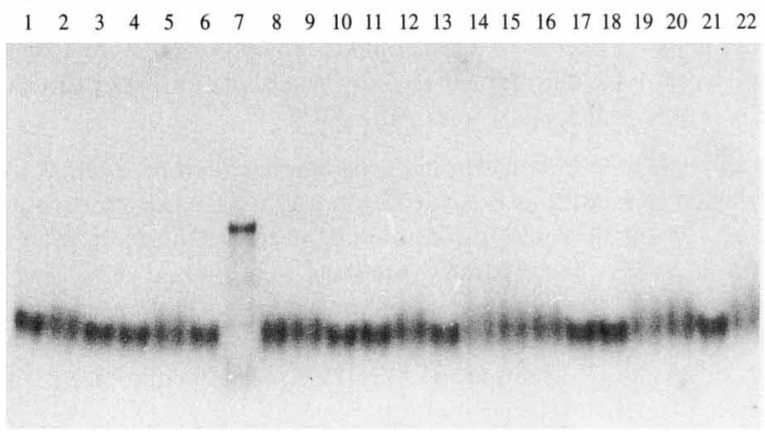

Fig. 1. Specificity of NASBA in combination with ELGA probes: (a) OT 999, $M$. tuberculosis probe; (b) OT 998, $M$. avium-paratuberculosis probe; (c) OT 997, $M$. intracellulare probe; and (d) OT 852, $M$. leprae probe. NASBA was performed using primers OT 727 and OT 737 on NA from bacterial species and strains listed in Table 1. Lane 22 contained human NA. The negative control samples used in this assay contained no target. After 'in-solution' hybridization (ELGA) of the NASBA product with the species-specific ELGA probes, the hybridization reaction mixtures were run in a 7\% acrylamide gel, to separate the free ELGA probe (fast mobility) from the homologous hybridized NASBA product (slow mobility). 
(a)

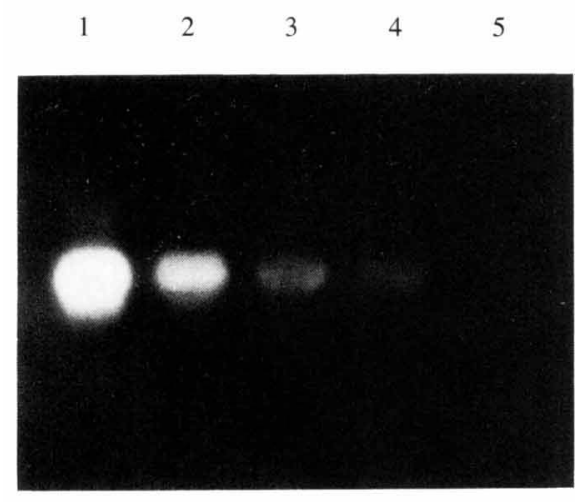

(b)

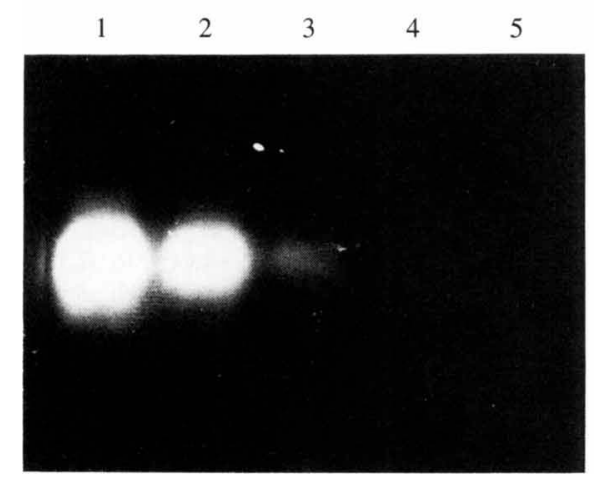

Fig. 2. Sensitivity of the NASBA. NASBA and Southern blotting were performed as described in Methods. (a) Analysis of NASBA reactions containing total RNA purified from $M$. tuberculosis. The amount of total RNA added per NASBA reaction was $500 \mathrm{pg}$ (lane 1), $50 \mathrm{pg}$ (lane 2), $5 \mathrm{pg}$ (lane 3), $500 \mathrm{fg}$ (lane 4), and $50 \mathrm{fg}$ (lane 5). (b) Analysis of NASBA reactions performed on NA isolated from a suspension of $M$. tuberculosis. The number of bacteria per sample was as follows: $2 \times 10^{4}$ (lane 1), $2 \times 10^{3}$ (lane 2), $2 \times 10^{2}$ (lane 3), $2 \times 10^{1}$ (lane 4) and $2 \times 10^{0}$ (lane 5).

(Fig. 1b, lane 8). Probes OT 997 and OT 852 showed only hybridization with respectively amplified RNA from $M$. intracellulare (Fig. 1c, lane 5) and $M$. leprae (Fig. 1d, lane 7). The specificity of probe OT 851 for M. smegmatis was confirmed in a similar experiment (results not shown). No detectable signal was found when the ELGA was performed using each probe with amplification products derived from many other mycobacterial species or other bacteria which may be found in clinical samples (Fig. 1 $a, b, c, d$, lanes 11-21). No visible products were found in the reactions in which only human NA was added (Fig. 1 $a, b, c, d$, lane 22).

Based on seroagglutination, the $M$. avium-M. intracellulare complex can be divided in 28 different serovars; $M$. avium is represented by serovars 1 to 3 and $M$. intracellulare by serovar 4 to 28 (Schaefer, 1980).
Recently, the sequences of the 16S rRNA of different serovars belonging to the $M$. avium-M. intracellulare complex have become available (Böddinghaus et al., $1990 \mathrm{~b}$ ). The 16S rRNA sequences of $M$. intracellulare serovars 16 and 21-28 are still not known. Alignment of the known 16S rRNA sequences of the members of the M. avium-M. intracellulare complex with probes OT 998 and OT 997 suggests that probe OT 998 has the potential to detect all three $M$. avium serovars and $M$. intracellulare serovars 4-6 and 8-11; probe OT 997 detects $M$. intracellulare serovars $12-15$ and $17 / 19 / 20$. Since $M$. intracellulare serovars 7 and 18 are not identified by these two probes, an additional probe would be necessary to include these serovars also.

\section{Sensitivity of NASBA}

The sensitivity of the NASBA technique was investigated with $M$. tuberculosis as a model system. This was done by adding a 10 -fold serial dilution of purified total RNA derived from $M$. tuberculosis in amounts ranging from $5 \mathrm{ng}$ to $50 \mathrm{fg}$ to the reactions. A $500 \mathrm{fg}$ amount of total RNA could be amplified reproducibly to give a clearly detectable signal on a Southern blot using ${ }^{32} \mathrm{P}$-labelled probe OT 999 (Fig. 2a). In addition, 10-fold serial dilutions were made from a suspension of $M$. tuberculosis ranging from $10^{5}$ to 10 bacteria per NA extraction. Only a part of the extracted NA was subjected to the NASBA reaction: the final amount of NA derived from $2 \times 10^{4}$ to 2 bacteria was added. The addition of NA derived from 200 bacteria resulted in a visible band on a Southern blot using ${ }^{32} \mathrm{P}$-labelled probe OT 999 (Fig. 2b). A similar experiment using $M$. smegmatis and probe OT 851 revealed a detection level of approximately 20 bacteria (results not shown).

The effect of using the high copy number of rRNA on the sensitivity of the NASBA assay was not apparent. However, NASBA has been shown previously to be able to detect as little as 100 molecules of RNA (Kievits et al., 1991). Using the protocol described here we did not reach such high sensitivity. However, in our investigation emphasis was put on specificity rather than on sensitivity. Optimization of NASBA for the detection of low numbers of mycobacterial target rRNA molecules is now in progress.

A 10-fold difference in sensitivity of the NASBA method was observed using $M$. tuberculosis and $M$. smegmatis NA derived from whole bacteria as targets. Two reasons can be put forward to explain this observation. First, fast-growing mycobacteria such as $M$. smegmatis may contain a larger number of ribosomes than slow-growing mycobacteria such as $M$. tuberculosis. Thus, more rRNA per bacterium can be isolated from rapid growing mycobacteria (Ratledge, 1982). The higher 
content of rRNA per cell in fast-growing mycobacterial species may lead to a more sensitive detection limit using the NASBA technique. Secondly, the apparent reduced sensitivity of NASBA when using $M$. tuberculosis compared to $M$. smegmatis might be due to different culture conditions. $M$. tuberculosis was grown on a solid medium and $M$. smegmatis in a liquid medium. A colony grown on a solid medium comprises a larger proportion of non-viable bacteria than the same amount of bacteria grown in a liquid medium (Winder, 1982). With both explanations, it is assumed that the apparent difference in sensitivity of NASBA using different mycobacteria reflects a difference in 16S rRNA content of the bacteria. The content of 16S rRNA may be related to metabolic activity. If this is true, the NASBA technique has the potential to discriminate between dead and living bacteria by detecting the different RNA levels of the cells.

\section{Identification of different $M$. tuberculosis isolates}

Probe OT 999 was based on the 16S rRNA sequence of a single $M$. tuberculosis strain (Böddinghaus et al., $1990 a$ ). Therefore, different $M$. tuberculosis isolates were tested in this study. NASBA in combination with ELGA using probe OT 999 allowed identification of the $32 \mathrm{M}$. tuberculosis strains from clinical isolates from different parts of the world (16 from Tanzania, 8 from Thailand and 8 from The Netherlands). The correct identification by NASBA of these $M$. tuberculosis isolates from various sources shows the potential general applicability of this method. Further studies are necessary to evaluate whether this method can be used for the identification and possibly also detection of mycobacteria in biological specimens.

\section{Conclusion}

NASBA in combination with ELGA offers a less complicated and more rapid alternative to routine biochemical identification, as it can be used to identify cultured mycobacteria in less than $6 \mathrm{~h}$. The fact that NASBA does not require specialized equipment makes it an attractive method for simple settings. Additionally, NASBA has the potential to be used for detection and identification of mycobacteria (and other organisms) in biological specimens, since it meets the requirements of sensitivity, specificity and rapidity. This would have definite advantages over identification of phenotypic characteristics of cultured mycobacteria.

The authors wish to thank Drs Henk Smits and Ruud van Ketel for providing materials. We thank Irene Struiksma for her assistance in preparation of the manuscript. We acknowledge the financial support of the Q. M. Gastmann-Wichers Foundation, the Netherlands Leprosy
Relief Association and the Commission of European Communities Directorate General for Science, Research and Development (grant TS3-CT91-0036).

\section{References}

Bates, J. H. (1979). Diagnosis of tuberculosis. Chest 76 (Suppl.), 757-763.

Böddinghaus, B., Rogall, T., Flohr, T., Blöcker, H. \& Böttger, E. C. $(1990 a)$. Detection and identification of mycobacteria by amplification of rRNA. Journal of Clinical Microbiology 28, 1751-1759.

Böddinghaus, B., Wolters, J., Heikens, W. \& Böttger, E. C. $(1990 \mathrm{~b})$. Phylogenetic analysis and identification of different serovars of Mycobacterium intracellulare at the molecular level. FEMS Microbiology Letters 70, 197-204.

Boom, R., Sol, C. J. A., Salimans, M. M. M., Jansen, C. L., Wertheim-Van Dillen, P. M. E. \& VAN Der NoordaA, J. (1990). Rapid and simple method for purification of nucleic acids. Journal of Clinical Microbiology 28, 495-503.

Chirgwin, J. M., Przybyla, A. E., MacDonald, R. J. \& Rutter, W. J. (1979). Isolation of biologically active ribonucleic acid from sources enriched in ribonuclease. Biochemistry 18, 5294-5299.

Compton, J. (1991). Nucleic acid sequence-based amplification. Nature, London 350, 91-92.

Gonzalez, R. \& HanNA, B. A. (1987). Evaluation of Gen-Probe DNA hybridisation systems for the identification of Mycobacterium tuberculosis and Mycobacterium avium-intracellulare. Diagnostic Microbiology and Infectious Disease 8, 69-77.

Kievits, T., van Gemen, B., van StriJP, D., Schukkink, R., Dircks, M., Adriaanse, H., Malek, L., Sooknanan, R. \& Lens, P. (1991). NASBA $^{\mathrm{TM}}$ isothermal enzymatic in vitro nucleic acid amplification optimized for the diagnosis of HIV-1 infection. Journal of Virological Methods 35, 273-286.

Liesack, W., Pitulle, C., Sela, S. \& Stackebrandt, E. (1990) Nucleotide sequence of the 16S rRNA from Mycobacterium leprae. Nucleic Acids Research 18, 5558.

Meier, A., Persing, D. H., Finken, M. \& Böttger, E. C. (1993). Elimination of contaminating DNA with polymerase chain reaction reagents: implications for a general approach to detection of uncultured pathogens. Journal of Clinical Microbiology 31, 646-652.

RATLEDGE, C. (1982). Nutrition, growth and metabolism. Growth. Methods of laboratory culture. In The Biology of the Mycobacteria, chapter 5, III, A., p. 198. Edited by C. Ratledge \& J. Stanford. London: Academic Press.

Rogall, T., Wolters, J., Flohr, T. \& Böttger, E. C. $(1990 a)$. Towards a phylogeny and definition of species at the molecular level within the genus Mycobacterium. International Journal of Systematic Bacteriology 40, 323-330.

Rogall, T., FloHR, T. \& BöTtGer, E. C. $(1990 \mathrm{~b})$. Differentiation of Mycobacterium species by direct sequencing of amplified DNA. Journal of General Microbiology 136, 1915-1920.

SambrooK, J., Maniatis, T. \& Fritsch, E. (1989). Molecular Cloning: A Laboratory Manual, 2nd edn. Cold Spring Harbor, NY: Cold Spring Harbor Laboratory.

SCHAEFER, W. B. (1980). Serological identification of atypical mycobacteria. Methods in Microbiology 13, 323-344.

STAHL, D. A. \& Urbance, J. W. (1990). The division between fast- and slow-growing species corresponds to natural relationships among the mycobacteria. Journal of Bacteriology 172, 116-124.

STOKER, N. G. (1990). The polymerase chain reaction and infectious diseases: hopes and realities. Transactions of the Royal Society of Tropical Medicine and Hygiene 84, 755-758.

Telenti, A., Marchesi, F., Balz, M., Bally, F., Böttger, E. C. \& BODMER, T. (1993). Rapid identification of mycobacteria to the species level by polymerase chain reaction and restriction enzyme analysis. Journal of Clinical Microbiology 31, 175-178.

Teske, A., Wolters, J. \& BöttGer, E. C. (1991). The 16S rRNA nucleotide sequence of Mycobacterium leprae: phylogenetic position and development of DNA probes. FEMS Microbiology Letters 80, 231-238. 
Verstijnen, C. P. H. J., Ly, H. M., Polman, K., Richter, C., Smits, S. P., Maselle, S. Y., Peerbooms, P., Rienthong, D., MontreewaSuwat, N., Koanjanart, S., Trach, D. D., KuJjPER, S. \& KolK, A. H. J. (1991). Enzyme-linked immunosorbent assay using monoclonal antibodies for identification of mycobacteria from early cultures. Journal of Clinical Microbiology 29, 1372-1375.

WINDER, F. G. (1982). Mode of action of the antimycobacterial agents and associated aspects of the molecular biology of the mycobacteria. Rifampicin: an inhibitor of transcription. RNA polymerase: struc- ture and action. In The Biology of the Mycobacteria, chapter 8, II, A., p. 364. Edited by C. Ratledge \& J. Stanford. London: Academic Press.

WOESE, C. R. (1987). Bacterial evolution. Microbiological Reviews 51, 221-271.

World Health Organization. (1980). Purification of M. leprae. Report of the 5th Meeting of the Scientific Working Group on the Immunology of Leprosy (IMMLEP). TDR/IMMLEP-SWG(5)/80.3. Geneva: World Health Organization. 